\title{
IMPLEMENTATION GUIDANCE SERVICES GROUP TO OVERCOME INTROVERTED PERSONALITY
}

\author{
Khairul Amri ${ }^{1}$, Dian Hasfera ${ }^{2}$ \\ ${ }^{1}$ Lecturer of Guidance and Counseling, Universitas Muhammadiyah Tapanuli Selatan, South Sumatera, \\ Indonesia. \\ (khairul.amri@um-tapsel.ac.id) \\ ${ }^{2}$ Lecturer of Information and Library Science,Universitas Islam Negeri Imam Bonjol Padang, West \\ Sumatera, Indonesia. \\ (dianhasfera@uinib.ac.id)
}

\begin{abstract}
The study was based on concerns about the personality of the students in the school environment, especially regarding introvert (closed). The research goal is to overcome the introverted personalities of students in SMK Negeri 1 Padangsidimpuan through Guidance Services Group. The method used is a pre-experimental research with the shape of The One Group Pretest - Post Test Design. With a sample of experimental class is class XI Administration 1 as many as 10 students were 5 girls and 5 boys, so as the total sample of 10 students. Tutoring Services Group dilakukakan three meetings and one-time meeting information services, namely in the first meeting perform pretest and posttest perform all treatments. Data were analyzed using the Wilcoxon rank test signesd and Kolmogorov Smirnov 2 with the help SPSS version 20.00. From the results of operations to be carried, a decline in student introverted personalities are quite large, especially the second and third meetings. The findings in the experimental group there is a significant drop between the results of the posttest. to test the hypothesis used by the formula Wilcoxon signed rank test using SPSS version 20 o'clock Wilcoxon test was used to analyze the results of observations of the two data are different or not. On average variable introverted personalities of 142.6000 (posttest experiment) this looks very significant difference. The conclusion of this study the data processing, shows that the implementation of group counseling services can overcome introvert personalities. It is recommended for teachers to approach through group counseling, especially guidance to help shape the personality of students, both in learning, implementation and evaluation of learning. For further research, is expected to make a research on the introverted personalities through other methods
\end{abstract}

\section{PENDAHULUAN}

\section{Latar Belakang}

Dalam menghadapi masalah, remaja cenderung belum bisa menyelesaikan masalah dengan baik, sebab perilaku psikologis inilah yang dominan sebagian terbesar perilaku manusia merupakan perilaku yang dibentuk, perilaku yang diperoleh, perilaku yang dipelajari melalui proses belajar (Bimo W. 2002:99). Terlihat bahwa pemilihan strategi manajemen konflik erat kaitannya dengan tipe kepribadian.
Berdasarkan atas sikap jiwanya Menurut Abidin dan Suyasa (2003:94) manusia dapat digolongkan menjadi 2 tipe yaitu manusia yang bertipe ektrovert dan manusia bertipe introvert. kedua tipe tersebut masing-masing memiliki karakteristiknya sendiri-sendiri yang sangat berpengaruh terhadap perasaan, pikiran, minat serta sikap mereka. Antara ekstrovert dan introvert kadang-kadang mengelola konflik dengan cara yang berbeda karena keduanya memiliki orientasi yang berbeda. 
Beragam alternatif untuk mengatasi masalah tersebut diantaranya melalui layanan informasi,

layanan konseling perorangan dan layanan bimbingan kelompok. Layanan Bimbingan Kelompok bertujuan untuk mengembangkan kemampuan sosialisasi siswa, khususnya kemampuan komunikasi peserta layanan (Prayitno, 2004:101).

Salah satu upaya yang dapat dilakukan oleh guru pembimbing untuk mengatasi permasalahan keperibadian introvert (tertutup) adalah melalui layanan bimbingan kelompok. Layanan bimbingan kelompok adalah suatu cara memberikan bantuan (bimbingan) kepada individu (siswa) melalui kegiatan kelompok (Tohirin, 2009:170), Prayitno (dalam Tohirin, 2009:172) secara khusus layanan bimbingan kelompok bertujuan untuk mendorong pengembangan perasaan, pikiran, persepsi, wawasan dan sikap yang menunjang perwujudan tingkah laku yang lebih efektif, yakni peningkatan kemampuan bekomunikasi baik verbal maupun non verbal ditingkatkan.

\section{Identifikasi Masalah}

Berdasarkan latar belakang di atas, serta fenomena yang terjadi di sekolah maka penulis mengidentifikasikan masalah sebagai berikut ;

a. tidak aktif di kelas akibat kurangnya percaya diri

b. suka menyendiri

c. kurangnya hubungan komunikasi atar teman sebaya

\section{Batasan Masalah}

Agar penelitian ini terarah dan tidak menimbulkan kerancuan yang dikarenakan luasnya pembahasan juga keterbatasan peneliti dalam hal ini kemampuan dan pengetahuan untuk peneliti bermaksud membatasi masalah ini pada :
a. Pelaksanaan Layanan Bimbingan Kelompok
b. Kepribadian Introvert

\section{Perumusan Masalah}

Dari pembatasan masalah di atas, maka penulis merumuskan permasalahan sebagai berikut:

a. Apakah ada perbedaan kepribadian introvert siswa sebelum dan sesudah diberi layanan bimbingan kelompok ?

b. Apakah ada perbedaan layanan bimbingan kelompok dengan layanan informasi untuk mengatasi kepribadian introvert siswa?

\section{Tujuan Penelitian}

Berdasarkan rumusan masalah di atas, maka penelitian ini bertujuan untuk mendeskripsikan tentang:

a. Untuk mengetahui perbedaan kepribadian introvert siswa sebelum dan sesudah diberi layanan bimbingan kelompok

b. Untuk mengetahui perbedaan layanan bimbingan kelompok dengan layanan informasi untuk mengatasi kepribadian introvert siswa

\section{METODE}

Jenis penelitian yang dilaksanakan adalah penelitian kuantitatif dengan menggunakan metode eksperimen. Eksperimen adalah suatu cara untuk mencari hubungan sebab akibat (hubungan kausal) antara dua faktor yang sengaja ditimbulkan oleh peneliti dengan mengeliminasi atau menyisihkan faktor-faktor lain yang mengganggu. Eksperimen merupakan kegiatan yang direncanakan dan dilaksanakan oleh peneliti untuk mengumpulkan bukti-bukti yang berhubungan dengan hipotesis. Peneliti dapat menyimpulkan bahwa metode penelitian yang akan digunakan dalam penelitian ini adalah Pre-experimental dengan model pendekatan The One Group Pretest - Post Test Design yakni, eksperimen yang dilakukan pada satu kelompok tanpa kelompok perbandingan.

\section{a. Populasi}

A. Muri Y. (2007:183) menyatakan pula bahwa populasi adalah keseluruhan unit (yang 
telah ditetapkan) mengenai dan dari mana informasi yang diinginkan. Dalam penelitian ini yang menjadi populasi adalah kelas XI Administrasi SMK Negeri 1 Padangsidimpuan, yaitu kelas XI Adm 1 berjumlah 40 siswa.

Tabel. 1

Populasi

\begin{tabular}{|l|l|l|l|l|}
\hline \multirow{2}{*}{ No } & \multirow{2}{*}{ Kelas } & \multicolumn{2}{|l|}{ Jumlah Siswa } & \multirow{2}{*}{$\begin{array}{l}\text { Total } \\
\text { Siswa }\end{array}$} \\
\cline { 2 - 5 } & Perempuan & $\begin{array}{l}\text { Laki- } \\
\text { laki }\end{array}$ & \\
\hline 1. & $\begin{array}{l}\text { XI } \\
\text { ADM-1 }\end{array}$ & 30 & 10 & 40 \\
\hline \multicolumn{2}{|l|}{ Jumlah } & 40 \\
\hline
\end{tabular}

\section{b. Sampel}

Menurut A. Muri Y. (2007:149), secara sederhana dapat dikatakan bahwa sampel adalah sebagian dari populasi yang mewakili populasi tersebut.

Berdasarkan hasil secara random maka peneliti menetapkan kelas XI Adm - I berjumlah 10 siswa yaitu 5 siswa perempuan dan 5 siswa laki-laki yang merupakan kelas eksperimen. Adapun jumlah sampel keseluruhan adalah 10 siswa.

Tabel 2

Sampel

\begin{tabular}{|l|l|l|l|l|l|}
\hline No & Kelas & \multicolumn{2}{|l|}{ Jumlah siswa } & Total siswa & Ketrangan \\
\cline { 3 - 5 } & & Perempuan & $\begin{array}{l}\text { Laki- } \\
\text { laki }\end{array}$ & & \\
\hline 1 & $\begin{array}{l}\text { XI } \\
\text { ADM } \\
-1\end{array}$ & 5 & 5 & 10 & Eksperimen \\
\hline \multicolumn{2}{|l|}{ Jumlah } & & & \\
\hline
\end{tabular}

\section{c. Teknik Pengumpulan Data}

Untuk memperoleh data atau informasi tentang pelaksanaan layanan bimbingan kelompok untuk mengatasi kepribadian introvert menggunakan alat antara lain kertas, pulpen dengan teknik pengumpulan data berupa angket/kuesioner. Menurut A. Muri Y. (2007: 252) angket (kuesioner) berasal dari bahasa latin yaitu Questionnaire, yang berarti suatu rangkaian pertanyaan yang berhubungan dengan topik tertentu, diberikan kepada sekelompok individu dengan maksud untuk memperoleh data.

\section{d. Teknik Analisis Data}

Teknik analisis statistik non-parametric yang digunakan untuk menguji dalam penelitian ini adalah uji jenjang bertanda Wilcoxon signed ranks test. Pengujian hipotesis dengan cara uji jenjang bertanda dilakukan apabila peneliti ingin memastikan tentang ada tidaknya perbedaan kondisi setelah perlakuan tertentu diberikan.

Menurut Muhibbin S. (2010:153) Untuk mengetahui pada kategori mana masing-masing variabel penelitian berada, maka nilai rata-rata perolehan dari setiap variabel dibandingkan dengan klasifikasi penilaian yang ditetapkan

\section{HASIL}

Telah dilaksanakan pada siswa kelas XI Administrasi SMK Negeri 1 Padangsidimpuan sebanyak 10 orang sebagai sampel. Kelompok eksperimen 10 orang yang terdiri atas 5 perempuan dan 5 laki-laki, berdasarkan perhitungan secara Random. Untuk pelaksanaan perlakuan dilaksanakan dalam waktu yang berbeda.

Berdasarkan data yang diperoleh, maka dapat dideskripsikan hasil penelitian sebelum dilakukan perlakuan ( pretest) dan setelah diberikan perlakuan (posttest), dimana pengolahan data kuantitatif dilakukan dengan menggunakan bantuan SPSS versi 20.0 for windows.

Tabel 3

Perbandingan Hasil Penelitian Kepribadian Introvert

\begin{tabular}{|l|l|l|l|}
\hline \multirow{2}{*}{ No } & \multirow{2}{*}{ Indikator } & \multicolumn{2}{|c|}{ Eksperimen } \\
\cline { 3 - 4 } & & Pretest & Posttest \\
\hline
\end{tabular}




\begin{tabular}{|c|l|l|c|c|}
\cline { 2 - 4 } 1 & \multicolumn{2}{|l|}{ Pembawaan } & 290 & 347 \\
\hline 2 & \multirow{2}{*}{$\begin{array}{l}\text { lingkung } \\
\text { an }\end{array}$} & Sosial & 360 & 401 \\
\cline { 2 - 4 } & $\begin{array}{l}\text { Kelua } \\
\text { rga }\end{array}$ & 359 & 406 \\
\hline 3 & Kebudayaan & 249 & 272 \\
\hline \multicolumn{2}{|c|}{ Jumlah } & 1258 & 1426 \\
\hline
\end{tabular}

Data di atas diambil dari hasil tabulasi per indikator prestest-posttest eksperimen dan dengan adanya tabel perbandingan di atas dapat dilihat terjadinya peningkatan sebelum dan sesudah diberikannya perlakuan.

Dari tabel di atas jika di lihat dari hasil perbandingan interval yaitu sebagai berikut :

Tabel 4

Tabel perbandingan interval hasil

\begin{tabular}{|l|l|l|l|l|}
\hline No. & Nilai & \multicolumn{2}{|l|}{ Eksperimen } & Kategori \\
\cline { 3 - 4 } & Interval & Pretest & Posttest & \\
\hline 1. & $80-100$ & & 81 & $\begin{array}{l}\text { Sangat } \\
\text { Baik }\end{array}$ \\
\hline 2. & $70-79$ & 71 & & Baik \\
\hline 3. & $60-69$ & & & Cukup \\
\hline 4. & $50-59$ & & & Kurang \\
\hline 5. & $0-49$ & & & Gagal \\
\hline
\end{tabular}

Dilihat dari tabel di atas nilai perbandingan antara prestest-posttest eksperiemen. Yang terjadi adalah nilai dari posttest eksperimen lebih tinggi dibandingkan prestest eksperimen.

\section{PEMBAHASAN}

Adapun hasil pretest yang diperoleh pada kelas eksperimen masih belum diketahui. Maka hasil pretest tersebut dianalisis menggunakan pengolahan SPSS versi 20.0. Meyakini bahwa keperibadian menjadi bagian dari keberadaan sosok individu termasuk siswa di sekolah, tetapi bukan kepribadian introvert salah satunya yang harus ditanamkan pada diri siswa. Maka hendaknya perlu dilakukan upaya untuk membantu siswa menurunkan kepribadian introvert mereka. Layanan bimbingan kelompok bisa menjadi alternative upaya yang bisa dilakukan, karena bimbingan kelompok terbukti dapat menurunkan kepribadian introvert siswa.

Hasil pretest keposttest menunjukkan tidak ada perbedaan yang signifikan pada hasil keperibadian introvert siswa kelas eksperimen yang sebagian besar siswa memiliki keperibadian introvert dengan kategori baik (tinggi). Setelah layanan bimbingan kelompok diberikan (posttest) pada kelompok eksperimen, tingkat keperibadian introvert siswa menurun. Hal ini dapat dilihat juga pada tabel 3, dimana siswa yang semula memiliki keperibadian introvert baik ( $71 \%$ ) dan meningkat menjadi sangat tinggi ( $81 \%$ ).

Peningkatan hasil prestest dan posttest disebabkan karena perlakuan layanan bimbingan kelompok yang diberikan oleh konselor. Melalui layanan bimbingan kelompok, siswa merasakan bebasnya menyampaikan pendapat, dapat mengembangkan perasaan, pikiran, persepsi, wawasan dan sikap yang menunjang tingkah laku untuk mengendalikan diri, tenggang rasa dan sumbang saran kepada sesama anggota kelompok. Siswa dalam kegiatan layanan ini banyak memperoleh hal baru yang sesuai dengan pendapat Prayitno (1995: 178) mengemukakan bahwa Bimbingan kelompok adalah Suatu kegiatan yang dilakukan oleh sekelompok orang dengan memanfaatkan dinamika kelompok. Artinya, semua peserta dalam kegiatan kelompok saling berinteraksi, bebas mengeluarkan pendapat, menanggapi, memberi saran, dan lain-lain sebagainya; apa yang dibicarakan itu semuanya bermanfaat untuk diri peserta yang bersangkutan sendiri dan untuk peserta lainnya.

Menurut Romlah (2001: 3) Layanan bimbingan kelompok dimaksudkan untuk memungkinkan siswa secara bersama-sama memperoleh berbagai bahan dari narasumber (terutama guru pembimbing) yang bermanfaat untuk kehidupan sehari-hari baik sebagai individu maupun sebagai pelajar, anggota keluarga dan masyarakat.

Berdasarkan kesimpulan di atas Layanan bimbingan kelompok merupakan media pengembangan diri untuk dapat berlatih berbicara, menanggapi, memberi menerima pendapat orang lain, membina sikap dan perilaku yang normatif serta aspek-aspek positif lainnya yang pada gilirannya individu dapat mengembangkan potensi diri serta dapat meningkatkan perilaku komunikasi antar 
pribadi yang dimiliki, dan melatih membentuk keperibadian individu. Berdasarkan hal tersebut maka kepribadian introvert dapat teratasi dengan menggunakan layanan bimbingan kelompok.

\section{SIMPULAN}

Kesimpulan dalam penelitian ini adalah layanan bimbingan kelompok dan layanan informasi sama-sama efektif untuk mengatasi keperibadian introvert, namun jika dibandingkan, layanan bimbingan kelompok lebih efektif dibandingkan layanan informasi. Terapat perbedaan penurunan keperibadian introvert kelompok eksperimen sebelum (pretest) dan sesudah (posttest) mengikuti kegiatan bimbingan kelompok, dimana rata-rata $71 \%$ sebelum perlakuan (pretest) dengan kategori baik, setelah diberikan perlakuan (post-test) mengikuti kegiatan bimbingan kelompok dimana rata-rata $81 \%$ dengan kategori sangat baik dalam penurunan keperibadian introvert siswa. Menurut Carl Gustav Jung adalah sebuah sifat dan karakter yang cenderung menyendiri. Mereka adalah pribadi yang tertutup dan mengesampingkan kehidupan sosial yang terlalu acak. Dengan demikian dapat dikatakan bahawa sesuai dengan teori Calr Gustav Jung Pelaksanaan Layanan Bimbingan Kelompok Untuk Mengatasi Kepribadian Introvert

\section{SARAN}

Berdasarkan kesimpulan tersebut di atas, maka peneliti memberikan saran-saran kepada:

a. Guru BK

a) Dapat memberikan layanan bimbingan kelompok sesuai dengan kebutuhan siswa, dan selalu mensosialiasasikan kegiatan bimbingan konseling di sekolah dengan diberikannya bimbingan kelompok akan membantu membentuk keperibadian siswa.

b) Membuat program layanan khususnya bimbingan kelompok hendaknya dapat memperhatikan hal sebagai berikut :
- Apa saja informasi yang dibutuhkan terkait persoalan/isi/kebutuhan siswa

- Apa saja tipe/jenis informasi yang dibutuhkan untuk bisa membantu klien yang efektif.

- Apa saja prosedur Asesmen dan teknik yang paling efektif dan efisien untuk memperoleh jenis informasi tersebut.

- Bagaimana cara hasil Asesmen tersebut dapat diorganisasikan dan diaplikasikan guna membuat program dan memenuhi kebutuhan klien secara efektif dan efisien.

b. Siswa

Berpartisipasi dan berperan aktif dalam upayaupaya yang dilakukan pihak sekolah untuk membantu mengembangkan potensinya demi kebaikan masa depannya. Artinya peserta didik dapat mengikuti program-program yang ditawarkan oleh pihak sekolah demi peningkatan dan penyelesaian masalah.

\section{c.Kepala Sekolah}

Sebagai pengambil kebijakan, kepala sekolah hendaknya memberikan kesempatan pada guru bimbingan dan konseling dalam masuk ke kelas agar dapat mengdiagnosa secara cepat permasalahan yang berkenan dengan keperibadian siswa. Khususnya menangani keperibadian introvert siswa.

\section{d.Peneliti Lanjutan}

Disarankan untuk memperluas jumlah sampel yang digunakan dan perlu dilakukan yang sama dengan mempelajari kelemahan-kelemahan dalam penelitian ini, ataupun dengan mengembangkan penelitian ini dengan dilatarbelakangi oleh konteks yang berbeda agar dapat membandingkan temuan dari hasil penelitian ini.

\section{DAFTAR RUJUKAN}

Ahmad Salim Badwilan. (2010). Cara Mudah Bisa Menghafal Alquran. Jogjakarta: Bening

W,Ahsin.(1994). Bimbingan Praktis Menghafal Alquran. Jakarta: Bumi Aksara 
Nasional, Departemen Pendidikan. (2005). Kamus Besar Bahasa Indonesi, Jakarta: Balai Pustaka

Moleong, Lexy J. (2005).Metodologi Penelitian Kualitatif, Bandung: PT Remaja Rosdakarya

Yunus, Mahmud. (1990).Kamus ArabIndonesia. Jakarta: Hidakarya Agung

Yayan, Masagus H.A. Fauzan. (2015). Quantum Tahfidz:etodeCepatdanMudahMenghafalA lquran. ttp: Erlangga

Huberman, Matthew B. Miles dan A. Michael. (1992). Analisa Data Kualitatif. Jakarta : UI-Press

Q, Sa'dulloh. S. (2008). 9 Cara Praktis Menghafal Alquran, Jakarta: Gema Insani

Silalahi, Ulber. (2010). Metode Penelitian sosial. Bandung : Refika Aditama

Wahid, Wiwi Alawiyah.(2010). Cara Cepat Bisa Menghafal Alquran. Yogyakarta:Andi Offset 